University of Nebraska - Lincoln

DigitalCommons@University of Nebraska - Lincoln

Center for Brain, Biology and Behavior: Papers \&

Publications

Brain, Biology and Behavior, Center for

8-1-2017

Lessons to be learned: how a comprehensive neurobiological

framework of atypical reading development can inform

educational practice

Ola Ozernov-Palchik

Xi Yu

Yingying Wang

Nadine Gaab

Follow this and additional works at: https://digitalcommons.unl.edu/cbbbpapers

Part of the Behavior and Behavior Mechanisms Commons, Nervous System Commons, Other Analytical, Diagnostic and Therapeutic Techniques and Equipment Commons, Other Neuroscience and Neurobiology Commons, Other Psychiatry and Psychology Commons, Rehabilitation and Therapy Commons, and the Sports Sciences Commons

This Article is brought to you for free and open access by the Brain, Biology and Behavior, Center for at DigitalCommons@University of Nebraska - Lincoln. It has been accepted for inclusion in Center for Brain, Biology and Behavior: Papers \& Publications by an authorized administrator of DigitalCommons@University of Nebraska - Lincoln. 


\title{
Lessons to be learned: how a comprehensive neurobiological framework of atypical reading development can inform educational practice
}

\author{
Ola Ozernov-Palchik ${ }^{1,2}$, Xi Yu ${ }^{1,3}$, Yingying Wang ${ }^{1,3}$, and Nadine Gaab ${ }^{1,3,4}$ \\ ${ }^{1}$ Laboratories of Cognitive Neuroscience, Division of Developmental Medicine, Department of \\ Medicine, Children's Hospital Boston, MA 02115, United States \\ ${ }^{2}$ Center for Reading and Language Research, Tufts University, Medford, MA 02155, United States \\ ${ }^{3}$ Harvard Medical School, Boston, MA 02115, United States \\ ${ }^{4}$ Harvard Graduate School of Education, Cambridge, MA 02138, United States
}

\begin{abstract}
Dyslexia is a heritable reading disorder with an estimated prevalence of 5-17\%. A multiple deficit model has been proposed that illustrates dyslexia as an outcome of multiple risks and protective factors interacting at the genetic, neural, cognitive, and environmental levels. Here we review the evidence on each of these levels and discuss possible underlying mechanisms and their reciprocal interactions along a developmental timeline. Current and potential implications of neuroscientific findings for contemporary challenges in the field of dyslexia, as well as for reading development and education in general, are then discussed.
\end{abstract}

\section{Introduction}

'Children are wired for sound, but print is an optional accessory that must be painstakingly bolted on' [Pinker in [1], p. ix-x].

Developmental dyslexia is a heritable neurobiological condition that is characterized by an unexpected failure to develop accurate or fluent reading and affects approximately $5-17 \%$ of children [2]. Individuals with dyslexia have shown structural and functional brain atypicalities in the complex reading network which consists of (1) left inferior frontal regions, (2) dorsal temporo-parietal regions, and (3) ventral occipital-temporal regions [3,4]. The etiological basis of dyslexia is not well understood due to the complex interactions among multiple genetic risk variants and environmental factors, which collectively affect typical and atypical reading development.

This paper aims to disambiguate the genetic, environmental, cognitive, and neurobiological components that are involved in predisposing a child to developing dyslexia. In particular, it

Corresponding author: Gaab, Nadine (nadine.gaab@childrens.harvard.edu).

Conflict of interest

Nothing declared. 
integrates current experimental evidence on the development of the reading brain with Pennington's [5] multiple deficit model (MDM) of developmental disorders and van Bergen's extended 'intergenerational multiple deficit model' of dyslexia [iMDM, $6^{*}$ ]. It further adds a developmental perspective to the current models and reviews specific factors and underlying mechanisms that contribute to atypical reading as well as their developmental trajectories prenatally and postnatally. Additionally it reviews and suggests relationships and interplays between the various levels and proposes a descriptive multicomponential model for the etiology of development of dyslexia which should be seen as an extension rather than a modification of the current models. Furthermore, current as well as potential implications of this framework for educational practice and policy are discussed.

\section{Genetics and the neurobiology of dyslexia}

Heritability of dyslexia has been estimated at approximately $60 \%[7,8]$. Interestingly, these estimates are much lower (20-33\%) if only siblings but no parents are affected, and higher (76-78\%) if both parents are affected [9].

Several candidate susceptibility genes for dyslexia (e.g. ROBO1, DCDC2, DYX1C1, KIAA0319) have been reported, the majority of which are involved in brain development $\left[10,11^{\circ}\right]$. A tentative pathway from genetic effects to developmental brain changes and to perceptual/cognitive deficits in dyslexia has been proposed [10]. According to this hypothesis, variant function in any number of genes involved in cortical development may lead to subtle cortical malformations involving neural migration and axonal growth, which in turn results in atypical cortico-cortical and cortico-thalamic circuits. Alterations in these circuits may be associated with the range of sensorimotor, perceptual, and cognitive deficits reported in dyslexia [5].

Studies in rodents and humans have demonstrated support for this hypothesis [12-16] and several studies have linked genetic with neuroimaging studies. It has been shown that experimental interference of the dyslexia susceptibility genes in rodents causes atypical neuronal migration, which in turn results in localized matter malformations that affect cortical circuitry [16,17]. For example, in utero disruption of KIAA0319 expression in rats has been shown to result in poor neural representation of speech sounds in the auditory cortex and in impaired performance on phoneme discrimination tasks $\left[18^{\circ}, 19,20\right]$. The reported behavioral impairments in these animal studies are similar to those observed in individuals diagnosed with dyslexia [e.g., 21], especially those who showed KIAA0319 and DCDC2 variants [22]. Additionally, studies in adults and children have shown that polymorphisms in dyslexia susceptibility genes are associated with structural temporoparietal gray and white matter alterations during development [13,23-25]. For example, a common variation near the dyslexia susceptibility gene $\mathrm{ROBO} 2$ has been associated with expressive vocabulary skills and the development of the posterior region of an interhemispheric white matter pathway (i.e., splenium) [26*0. The reported brain alterations observed in neuroimaging studies are consistent with the postmortem studies of individuals with dyslexia which revealed neural ectopias in various regions important for auditory and language processing as well as reading [24]. This cumulative evidence provides a robust 
support for an association between the dyslexia susceptibility genes and brain function and structural crucial for learning to read.

While more work needs to be done to identify the genes that are specifically linked to dyslexia, advances in our 'tool sets' for genetic analyses have vastly expanded our overall understanding of the genetics of developmental disorders such as dyslexia. For instance, research has highlighted the importance of generalist genes that are expressed throughout the brain and the nervous system, and are associated with broad cognitive functions important for learning. One such example is the COMT gene, which is involved in major metabolic functions in the brain and has been linked to general cognitive processes, such as executive function [27,28] and reading [29]. Another example is the FOXP2 gene that has been linked with disorders of speech and language, as well as dyslexia. It functions during the transcription of other genes and is thus expressed in multiple regions of the brain [30]. Discovery of the generalist genes explains the strong association in performance between reading and other domains such as language and mathematics, as well as the frequency of comorbidities between dyslexia and other disorders. This suggests that reading disability and other learning disabilities are in part governed by learning mechanisms with a general genetic basis [31,32]. Most importantly, a variety of genes have been identified that function at different time points of neurodevelopment and affect various developmental stages such as neuronal proliferation or interneuron migration, thus implicating a number of cell biological pathways critical for typical early brain development [33].

Genetically pre-determined brain structure is not fixed across development; rather, genetic makeup provides a mere blueprint for the brain architecture that serves as the basis for processing information in the environment [34]. Thus, it remains debated which brain characteristics of dyslexia predate the onset of reading instruction and which are a result of reduced reading practice (e.g. due to the daily struggle to read).

\section{Structural and functional brain alterations in dyslexia and their emergence}

Learning to read requires the coordination of an ensemble of sensory and cognitive systems, which are utilized to form the left-hemispheric neural reading circuit. A tentative model of reading development suggests that when children start to learn single word reading, superior temporal regions that are specialized for phonological processing become increasingly connected with temporo-parietal regions important for the integration of orthography with phonology [35]. Following the development of the temporo-parietal circuit for linguistic structures, the ventral occipito-temporal circuit, including lateral extra-striate, fusiform, and inferior temporal regions, becomes specialized for print and rapid word processing (i.e., sight word recognition), and a putative visual word form area (VWFA) emerges [36,37]. Then, through extensive reading practice, the ventral circuit for reading becomes increasingly automatic. The anterior inferior frontal circuit also plays an important role in reading development, although its specific contribution is not yet well defined. It is associated with various reading-related functions, including phonological processing, speech planning, lexical access, semantics [38], and comprehension [39,40], as well as with general cognitive functions, such as attention and inhibition [41]. This circuit shows increased involvement with age and reading experience [42-45]. 
Magnetic resonance imaging (MRI) studies in children and adults with dyslexia commonly demonstrate reduced gray matter volume indices and cortical thickness, as well as hypoactivation in left-hemispheric temporo-parietal, occipito-temporal, and inferior frontal networks (Figure 1a,b) [46,47]. Children with dyslexia display this pattern of hypoactivation even when compared to younger children with equivalent reading skills [48,49], suggesting that the observed alterations are not due to delayed maturation but are instead unique brain characteristics of dyslexia. Several papers have reported, however, that at least some brain alterations in individuals with dyslexia are likely due to impoverished reading experience [50,51]. Dyslexia has further been associated with structural differences in left-hemispheric white matter organization (Figure 1c) [52-55,56"*] and reduced resting-state and task-based functional connectivity among regions important for reading has also been demonstrated $[57,58]$.

Dyslexia is thought to originate in genetically-driven cortical, sub-cortical, and white matter abnormalities. Accordingly, pre-reading children with a family history of dyslexia (FHD+) have exhibited atypical sulcal patterns (i.e. the arrangement, number, and size of primary cortical folds), possibly reflecting a less optimal organization of cortical function and white matter connectivity during prenatal development (Figure 1d) [59*0. Moreover, atypical neural connectivity, such as decreased white matter integrity in the arcuate fasciculus, a white matter tract connecting dorsal posterior and anterior regions, has been observed for FHD+ children as early as infancy [60*]. The notion of early atypical brain development has been further supported by several studies that showed aberrant neural responses in FHD+ infants when compared to controls. For instance, alterations in neural responses to basic speech sounds have been observed using Electroencephalography (EEG) in FHD+ newborns [61-65] and most importantly, in newborns who subsequently received a diagnosis of dyslexia [e.g., 61] or who showed atypical language and reading development in toddlerhood or elementary school $[62,63,66-68]$. Furthermore, at-risk preschoolers have demonstrated reduced gray matter volume and reduced cortical thickness in temporo-parietal and occipito-temporal regions $[51,69]$ as well as hypoactivation in these regions during phonological [70] and orthographic [71,72] processing. These neural alterations in regions critical for reading-related functions can further disrupt the development and specialization of the phonological and orthographic systems as well as the connectivity of these systems with each other and other higher order components of the reading network.

\section{Neuro-metabolic alterations in dyslexia}

Magnetic Resonance Spectroscopy (MRS) is a noninvasive in vivo technique that estimates the amounts of various brain metabolites by utilizing the fact that their individual resonance frequencies are all distinct from the dominant water peak. The previously reported evidence for atypical brain development in posterior left-hemispheric regions motivates the investigation of the biochemistry and metabolic aspects underlying structural and functional alterations observed in individuals with dyslexia. To date, several studies have examined the relationship between neurometabolites and reading in individuals with and without dyslexia. Most of these studies have examined either Choline (Cho) or Glutamate (Glu) and their relationship to reading abilities/disabilities $\left[7^{\bullet}, 74-76\right]$. Cho is a nutrient important for the synthesis of cell membranes and an indicator for de novo myelin and cell membrane 
synthesis [77]. Developmental studies have shown an increase in the first 3 months of life with a subsequent decrease most likely due to accelerated myelination, which incorporates Cho into macromolecules associated with myelin [78]. Several studies have shown increased levels of Cho in temporo-parietal regions in adults and children with dyslexia $\left[73^{\bullet}, 74-76\right]$. A relationship between poor phonological processing and increased Cho levels in adults was observed, and the $\mathrm{Cho} / \mathrm{Creatine}(\mathrm{Cr})$ ratio accounted for a unique proportion of variance in phonological decoding, after controlling for age, cognitive ability, and timed/untimed sightword reading [75]. A similar relationship was demonstrated in childhood, with findings of significant correlations of $\mathrm{Cho} / \mathrm{Cr}$ ratios with word reading and passage comprehension $\left[73^{\circ}\right.$ ]. It has been suggested that elevated Cho reflects an inability to properly incorporate Cho-containing molecules into myelin [79] or the loss/disruption of normal myelin, which would increase the availability of such Cho-containing compounds, as observed in dysmyelinating disorders [80].

The neurometabolite Glu is one of the primary excitatory neurotransmitters that is utilized throughout the brain. Thus, Glu is essential for various neural functions critical for perception, cognition, and memory [81,82] peaking in concentration at approx. 4-6 months before subsequently declining until a plateau around age 2 [83]. To date, only one study has examined the relationship between reading and Glu in humans and further compared children with dyslexia to controls $\left[7^{\circ}\right]$. The results showed that $\mathrm{Glu} / \mathrm{Creatine}(\mathrm{Cr})$ ratio significantly correlated with phonological awareness and vocabulary at age 7 and that children with dyslexia exhibited higher Glu/Cr ratios compared to controls, which has been suggested to reflect hyperexcitability. This hyperexcitability may play an important role in the etiology and symptomology of dyslexia [73 ${ }^{\circ}$, which has been supported by studies showing inconsistent trial-to-trial performance [84] and greater variability in neuroimaging studies [85], including brainstem responses [21], in individuals with dyslexia. Furthermore, this hypothesis is in line with animal studies observing that mutations of the dyslexia susceptibility gene DCDC2 can lead to hyperexcitability, such as spontaneous firing, reflecting atypical glutamatergic activity [86].

\section{Perceptual and cognitive deficits and risk factors of dyslexia}

The cognitive phenotype of dyslexia is heterogeneous [87]. Prior attempts to identify and describe dyslexia from a single deficit perspective were unsuccessful and instead a multideficit approach has been adopted by most researchers [5,88]. This approach views dyslexia as representing the interaction of multiple risks and protective factors resulting in distinct cognitive profiles along a continuum of severity of reading outcomes.

Studies examining infants and pre-reading children with a hereditary risk for dyslexia have identified atypical language development in these children, as they tend to show poor categorical speech perception, delayed onset of talking, shorter mean length of utterances, lower complexity of syllables produced, and poor receptive or expressive vocabulary [8991]. Longitudinal studies have further demonstrated the importance of these early language skills for the development of reading. However, these symptoms have also been observed in children with a subsequent diagnosis of specific language impairment or speech sound disorders, and could be a consequence of the high occurrence of comorbidities between 
dyslexia and language disorders [91-94]. Therefore, delayed language development in some children with dyslexia risk is likely indicative of a cumulative contribution of etiological factors for each disorder, rather than being a specific marker of dyslexia risk.

Differences between preschoolers with and without familial risk for dyslexia have been identified on tasks measuring phonological awareness, verbal working memory, rapid automatized naming (RAN), and letter knowledge [95-97]. Phonological awareness is the meta-understanding of the sound units of oral language [98]. Verbal working memory is the memory system that is involved in the storage and active processing of current information [99]. Both have shown a significant association with a genetic (familial) risk for dyslexia as well as with the actual reading outcomes $\left[100^{*}, 101\right]$. A stepwise pattern of performance on these measures is commonly observed, with at-risk children with typical literacy outcomes performing worse than no-risk readers, but better than at-risk children with a subsequent dyslexia diagnosis [90,102-104]. RAN represents the ability to rapidly retrieve the name of visually presented familiar items in a serial array $[105,106]$ and has been shown to be a robust predictor of actual reading outcomes (particularly reading fluency), especially in poor readers $[102,107]$. Letter knowledge measured in kindergarten is the most robust, but ephemeral (i.e. it loses its predictive accuracy beyond kindergarten), predictor of reading ability $[108,109]$. However, since it is strongly influenced by environmental factors, such as home literacy and preschool enrollment, letter knowledge may predominately reflect lack of experience rather than a cognitive deficit in dyslexia [110].

Atypicalities in lower-level auditory or visual magnocellular processing in individuals with dyslexia have also been reported [111-116]. Several studies have demonstrated atypical auditory processing of slowly varying acoustic signal and rapid auditory processing in prereading children at risk for dyslexia [62,116-119]. Individuals with dyslexia demonstrated poor ability to process short sounds and stimuli with brief transitions [120,121]. Because brief frequency transitions are important for discriminating linguistic units, it has been suggested that the phonological deficit in dyslexia stems from this lower-level sensory impairment [113]. More recently, studies reported impaired discrimination of rise time cues (a rate of amplitude change) in speech in individuals with dyslexia. These cues are important for detection of speech rhythm and prosody [122,123]. Additionally, individuals with dyslexia have been shown to perform poorly on musical rhythm discrimination and reproduction tasks [124]. Difficulty with perceiving stress cues and rhythm in speech could undermine the ability to develop adequate representations of phonemes, thereby impairing the development of phonological awareness skills $[114,125]$. Studies examining visual and magnocellular processing in pre-reading children have failed to reach consensus, and increasing evidence points to this deficit being a result of limited reading practice rather than an underlying deficit in the magnocellular visual pathway [126-128].

Finally, some studies provided modality-general explanations of dyslexia such as poor perceptual learning [129] and poor temporal synchronization [130]. Deficits in attention and executive function have also been demonstrated [131-133]. Since reading development and performance requires cross-modal integration, these cross-modal mechanisms play a significant role in the development of phonological and orthographic abilities and in fluent reading [130]. 


\section{Environmental influences and risk factors of dyslexia}

Environment has a strong influence on brain and cognitive [134-136,137 $\left.{ }^{\bullet}, 138-140\right]$. Prenatal factors such as maternal stress, smoking, and alcohol consumption, can affect cortical development and neural migration [141]. Children's postnatal early environment is largely shaped by cultural and parental characteristics and the environment has a significant influence on the trajectory of brain development in childhood and through adolescence $\left[134-136,137^{\bullet}, 138-140\right]$. The development of brain regions that support language, reading, and executive functions are particularly affected by socioeconomic factors [135,137\%" $]$. Poor environmental conditions can exert unfavorable influence on children who are genetically predisposed for dyslexia increasing the likelihood of later reading failure [101,142]. Parents with lower educational background and socioeconomic status (SES) tend to have fewer books at home, and spend less shared reading time with their children [143] This home literacy environment affects the development of early reading skills [110,144,145], particularly in families with low SES [146,147].

Besides individual households, negative neighborhood features such as high concentration of poverty and high family density, have imposed adverse effects on children's vocabulary and letter knowledge, both directly $\left[148,149^{\circ}\right]$ and indirectly via parental interaction $[150,151]$. At the onset of schooling, ineffective instructional practices, negative social perception, limited instructional resources, and other adverse academic factors may further exacerbate poor reading development in children [152,153]. Moreover, lack of parental awareness may result in negative parent-child interactions and poor psychological outcomes for the child [154]. Lack of awareness can also prevent parents and teachers from seeking effective resources for intervention and result in delayed identification of dyslexia risk [155].

Overall, environmental factors were shown to explain up to $30 \%$ of individual differences in reading [156-158]. Environmental components interact with each other in conjunction with genetic factors to form a reciprocal process creating long-lasting effects extending over generations [142]. Individuals with dyslexia are less likely to complete high school [159**], pursue higher education [160], and are at an increased risk of entering the justice system [161]. Children of these individuals would subsequently be both at a higher genetic and environmental risk.

\section{Protective factors and compensatory mechanisms}

Dyslexia is a persistent condition that affects individuals throughout their lifetime. Many adults with a childhood diagnosis of dyslexia never develop fluent or proficient reading skills. Others become functional readers, but still suffer from residual difficulties in spelling, phonemic awareness, and fluency [162-164]. The latter group is often referred to as compensated dyslexic readers or resilient readers. The mechanisms through which these individuals achieve reading competency are not well investigated or understood [165]. Nevertheless, several cognitive and environmental protective factors have emerged in the literature including high intelligence, rich vocabulary, strong reliance on semantic context, large visual memory, strong reasoning skills, and the ability to maintain attention $\left[166,167,168^{\circ *}, 169\right]$. 
Brain studies of compensated individuals have demonstrated that these individuals recruit additional regions not evident in typical controls or individuals with persistent dyslexia. For example, increased activation in the right inferior frontal gyrus (Figure 1b) has been reported across several studies during phonological processing in compensated individuals with dyslexia $[164,170-172]$ and in response to intervention [173 ${ }^{\circ}$.

\section{A proposed integrative model}

As discussed, dyslexia is an outcome of multiple risks and protective factors interacting at the genetic, neural, cognitive, and environmental levels. Therefore, a multidimensional etiological model is necessary for understanding dyslexia. Pennington [5] has proposed the multiple deficit model (MDM) of learning disabilities in which multiple etiological factors interact probabilistically to increase the liability for a disorder in a continuous and quantitative manner. Specifically, genetic and environmental factors interactively affect neural systems that in turn affect multiple cognitive processes, which together result in a risk profile for a single developmental disorder or multiple disorders. The MDM model provides a general framework for explaining comorbidity among developmental disorders, but it does not specify the components of each of the multifactorial levels of influence or their developmental trajectories. Van Bergen and colleagues [6] have extended the MDM into an intergenerational MDM (iMDM) by adding the intergenerational transmission of risk and of protective factors for learning disabilities. The extended model iMDM specifies the cognitive and familial environmental risk factors for dyslexia. It predicts a continuum of liability distribution for dyslexia and emphasizes the importance of parental cognitive abilities for evaluating risk in children.

The current paper further expands on MDM and iMDM by adopting a developmental approach and by specifying factors and mechanisms that contribute to the development of dyslexia. Figure 2 summarizes the components for each of the levels outlined by Pennington and van Bergen and further integrates them in a developmental framework that specifies the importance and sequel of these specific factors and mechanisms at each time point on the developmental axis as well as their developmental trajectories. Experimental evidence from neuroimaging, genetic, and behavioral studies has been incorporated to illustrate the independent significance of each of the components for dyslexia but also their reciprocal relationship. We hypothesize that this interplay between the various levels on the developmental axis determines the location(s) of the brain alterations, the severity of the alterations and the connectivity strength between brain structures that support reading. These factors can further adversely influence neural responses and the development of cognitive functions. These interplays most likely vary tremendously depending on the developmental time point and are strongly influences by a child's environment. This is supported by studies that suggest that with the concomitant exposure to poor home literacy or instructional quality, the likelihood of FHD+ children to develop dyslexia further increases [142]. Although in the current paper psychological factors (e.g., motivation, self-efficacy) in dyslexia were not reviewed, they are nevertheless important and can serve as additional exacerbating or protective influences on reading development [174]. 


\section{Implications for educational practice and policy}

It is important to exercise caution when attempting to translate findings from neuroscience to practices in education and policy. Misinterpretation and over-simplification of data can cause persistent neuromyths [175] that can in turn be used to justify inadequate practices [176]. Nevertheless, since the potential gains are invaluable, the task of attempting to translate emerging findings in the prolific field of dyslexia research to real-world practices is worth undertaking. Here, we highlight several contemporary challenges in education and discuss the potential role of neuroscience in addressing these.

\section{Can neuroscience inform a definition of dyslexia?}

The high behavioral heterogeneity of dyslexia prompted some to suggest to eliminate the term dyslexia all together [2]. Neuroimaging studies are beginning to inform several of the most contentious questions historically faced by the field: for instance, the field has debated whether a multi-deficit view of dyslexia should be accepted. Several studies so far have demonstrated that literacy skills such as PA and RAN are associated with distinct neuroanatomical regions [177-179] and that children with different profiles of deficit on these skills have unique patterns of activation during a reading-related task [180]. This supports the multi-deficit approach to dyslexia by suggesting that distinct brain mechanisms are associated with the various dyslexia profiles.

\section{How do environmental factors influence a brain's ability to read?}

Environment has a powerful impact on brain development both prenatally and postnatally. In the case of dyslexia, language and literacy environments can both predispose children for reading failure and potentially protect them despite a genetic risk. Policies and interventions that encourage parents to optimize their home literacy environment, by increasing shared reading time and using rich child-directed speech, have been shown to have important positive impacts on language and reading outcomes $[110,181]$. Neuroscience can play several important roles in this domain. It can, for example, shed light on the underlying mechanism through which environmental factors influence reading circuitry. For instance, a relationship between home reading exposure and activation in left-hemispheric posterior regions of the reading network as well as brain areas supporting mental imagery and narrative comprehension has been recently demonstrated [182]. This in turn can inform (a) the development of specific interventions that focus on certain aspects of home language and literacy and (b) teaching practices in the classroom, especially for children with reduced language and home literacy exposure. Furthermore, imaging can potentially assist in quantifying the influence of environmental variables on the development of language and pre-reading networks in infants, at an age where standardized behavioral language measures often fail.

\section{Is it feasible to utilize neuroscience for the early identification of dyslexia risk?}

Emerging evidence suggests that neuroimaging can enhance the prediction of reading outcomes over behavioral measures $\left[61,63,66-68,170,183,184^{* *}, 185\right]$. Furthermore, early neural alterations in dyslexia seem to predate reading onset and reflect the differential developmental trajectory of reading brain networks as the result of genetic predisposition for 
dyslexia. However, to date, these alterations cannot serve as early biomarkers, and it is unclear whether we will ever have reliable biomarkers with appropriate levels of specificity and sensitivity. Nevertheless, if proven cost-efficient and if specificity and sensitivity are maximized, there may be the possibility to utilize neuroimaging to enhance the accuracy of early identification of risk most likely in a clinical setting. While several behavioral measures show promise in predicting which children will develop dyslexia even before reading onset $[95,186]$, early identification requires a trade-off between specificity (i.e., reducing the rate of false positives) and sensitivity (i.e., reducing the rate of false negatives) of identification, which can often result in high rates of over/under-identification. An assessment battery for early identification that consists of behavioral measures as well as neuroimaging measures may be able to maximize the specificity and sensitivity with subsequent important implications for educational practice and policy.

\section{When is the best time to intervene for atypical reading development?}

It has been shown that targeted literacy interventions are most effective when administered in kindergarten and first grade $[187,188]$. Across six studies, after receiving intensive instruction (number of instruction hours ranged from 30 to over 300 across studies), 56-92\% of the at-risk beginning readers reached the range of average reading ability [187]. A metaanalysis comparing early intervention studies offering at least 100 sessions, reported larger effect sizes for intervention studies conducted with kindergarten and first graders than with children in 2nd and 3rd grades [188]. While these results strongly favor a customized intervention as early as possible, it may be possible to utilize neuroimaging to determine the optimal window of intervention in each child based on (individualized) neuroimaging measures of brain development.

\section{Can brain measures assist us in determining school readiness?}

Ensuring that all children enter school ready to learn is in important goal of education and policy [189]. School readiness is a multi-dimensional construct with many levels of intrinsic and environmental influences, and it has been suggested that one-dimensional behavioral measures attempting to capture whether a child possesses the emotional, behavioral, and cognitive skills needed to thrive in school are imprecise [190]. Additionally, performance on specific tasks, such as reading, is an outcome of multiple systems. For example, cognitive control, a strong predictor of school readiness, is closely linked with the affective system, but can also influence performance on behavioral measures of pre-literacy [189]. While poor cognitive control or 'affective immaturity' may indicate the need to delay school start and retain the child in a more intimate and individualized preschool setting, poor pre-literacy skills can instead signal the urgency for the formal literacy instruction available in kindergarten. Additionally, as discussed, neuroimaging methods can potentially reveal which specific neural systems are protracted in development or follow an alternative developmental trajectory in a particular child and therefore may inform decision-making.

\section{What factors are important for shaping a 'resilient' reading brain?}

As described above, several studies reported potential compensatory mechanisms that influence typical reading development in at-risk children. It remains unclear what the role of these compensatory regions is during the development of typical reading, under which 
circumstances they form, if they are present prior to the onset of reading, and most importantly, which environmental or instructional factors may stimulate or hinder these alternative pathways. The answer to these questions can potentially inform a variety of educational decisions and help to build customized interventions. Children who grow up under adverse circumstances often display numerous brain alterations that affects a variety of neural circuits including the language and reading circuit $\left[137^{\circ}, 191\right]$. Neuroimaging can shed light on the relationship between protective environmental factors and the development of the reading network, for example, and most importantly its timeline in order to highlight and inform preventive strategies and interventions (e.g., does enhanced home literacy in infancy 'remediate' early atypical reading circuitry in children from low socioeconomic backgrounds?).

\section{Which atypical reading brain learns best under which circumstances?}

The multi-deficit view of dyslexia necessitates that intervention studies are individualized in order to optimize outcomes. Indeed, intervention studies have shown that treatment efficiency varies based on individual profiles of dyslexia [192,193]. Neuroimaging methods have revealed the potential to identify the unique differences across individuals with disorders, such as dyslexia, and relate those differences to future behavioral outcomes $\left[194^{*}\right]$. For example, it has been shown that spatio-temporal brain activation profile in temporo-parietal regions, as measured with magnetoencephalography (MEG), prior to reading intervention in children with dyslexia predicted which children will actually benefit from the given intervention [195]. This suggests that children with neurobiological profiles that are more typical are more likely to respond well to intervention [173] and further highlights the role of compensatory neural mechanisms. In the future, neuroimaging may be utilized to determine which brain will benefit best from which intervention.

\section{Conclusion}

The current state of understanding the etiological basis of dyslexia requires cautious optimism. There is emerging understanding of each of the genetic, cognitive, neural, and environmental levels as well as the interaction among these levels. The appreciation of the complexity of dyslexia can offer multiple insights for further investigation and translation. Embracing a multifactorial model of dyslexia encourages greater interdisciplinary and a multiple-componential approach to studying and treating dyslexia.

Most importantly, using so called 'brain-based' tools in education for prediction and intervention is still out of reach (and may even be proven to be unfeasible). The limited number of studies, small sample sizes, and differences in criteria for defining dyslexia across neuroimaging studies hinder the generalizability of findings and their application to clinical population. Additionally, while neural measures enhance the overall prediction accuracy of behavioral measures, their additional contribution to date has been moderate and a costefficiency model weighing important factors such as benefits and high costs of neuroimaging has not been computed yet.

Due to the complexity described above, the application of neuroscience in education has been described 'a bridge too far' [196]. Indeed, historically, attempts to translate research 
findings to 'real-world' practices have been ridden with dubious brain-based recipes for practice and premature misinterpretations of data $\left[176,197^{\circ}\right]$. Furthermore, there has been some resistance from practitioners to the one-sidedness with which scientific knowledge has been handed down from research labs into schools. Yet, cross-disciplinary research, described above for dyslexia, has become increasingly popular and prolific. As a result, much advancement important for education and policy has been made. With this paper we hope to contribute to an increasing body of knowledge on how neuroscience research can be integrated with applied work in early identification, prevention and intervention of dyslexia, thereby maximizing intellectual and psychological outcomes for those at-risk for dyslexia.

\section{Acknowledgments}

We thank Nikola Nowack, Meaghan Mauer, Talia Raney, Udani Sandanayaka, and Jennifer Zuk for their assistance with the manuscript. This work was funded by 1R01HD065762 and 1R01HD067312 (NICHD), the William Hearst Fund, Harvard Catalyst (5UL1RR025758), the Charles Hood foundation and a pilot grant from Boston Children's Hospital (all to NG), and Evans Literacy Fellowship (to OOP).

\section{References and recommended reading}

Papers of particular interest, published within the period of review, have been highlighted as:

- of special interest

- of outstanding interest

1. McGuinness, D. Why Our Children Can't Read, and What We Can Do About it: A Scientific Revolution in Reading. Simon and Schuster; 1997.

2. Elliott, JG.; Grigorenko, EL. The Dyslexia Debate. Cambridge University Press; 2014. p. 14

3. Richlan F, Kronbichler M, Wimmer H. Functional abnormalities in the dyslexic brain: a quantitative meta-analysis of neuroimaging studies. Hum Brain Mapp. 2009; 30:3299-3308. [PubMed: 19288465]

4. Richlan F, Kronbichler M, Wimmer H. Structural abnormalities in the dyslexic brain: a metaanalysis of voxel-based morphometry studies. Hum Brain Mapp. 2012

5. Pennington BF. From single to multiple deficit models of developmental disorders. Cognition. 2006; 101:385-413. [PubMed: 16844106]

6••. van Bergen E, van der Leij A, de Jong PF. The intergenerational multiple deficit model and the case of dyslexia. Front Human Neurosci. 2014:8. This paper summarized Pennigton's multiple deficit model (MDM) of learning disabilities in which multiple etiological factors interact probabilistically to increase the liability for disorder in a continuous and quantitative, rather than categorical manner. It extended the model to an inter-generational MDM by integrating environmental and genetic inter-generation transmission factors.

7. Harlaar N, Spinath FM, Dale PS, Plomin R. Genetic influences on early word recognition abilities and disabilities: a study of 7-year-old twins. J Child Psychol Psychiatry. 2005; 46:373-384. [PubMed: 15819646]

8. Friend A, DeFries JC, Olson RK. Parental education moderates genetic influences on reading disability. Psychol Sci. 2008; 19:1124-1130. [PubMed: 19076484]

9. Gilger JW, Hanebuth E, Smith SD, Pennington BF. Differential risk for developmental reading disorders in the offspring of compensated versus noncompensated parents. Read Writing. 1996; 8:407-417.

10. Galaburda AM, LoTurco J, Ramus F, Fitch RH, Rosen GD. From genes to behavior in developmental dyslexia. Nat Neurosci. 2006; 9:1213-1217. [PubMed: 17001339]

11 . Kere J. The molecular genetics and neurobiology of developmental dyslexia as model of a complex phenotype. Biochem Biophys Res Commun. 2014; 452:236-243. This review 
summarized evidence for the genetic etiological basis of dyslexia, and described the important biological mechanisms that underlie atypical brain development in dyslexia and the methods used to study these mechanisms. [PubMed: 25078623]

12. Eicher JD, Gruen JR. Imaging-genetics in dyslexia: connecting risk genetic variants to brain neuroimaging and ultimately to reading impairments. Mol Genet Metab. 2013; 110:201-212. [PubMed: 23916419]

13. Marino C, Meng H, Mascheretti S, Rusconi M, Cope N, Giorda R, Molteni M, Gruen JR. DCDC2 genetic variants and susceptibility to developmental dyslexia. Psychiatric Genet. 2012; 22:25.

14. Newbury D, Paracchini S, Scerri T, Winchester L, Addis L, Richardson AJ, Walter J, Stein J, Talcott J, Monaco A. Investigation of dyslexia and SLI risk variants in reading-and languageimpaired subjects. Behav Genet. 2011; 41:90-104. [PubMed: 21165691]

15. Pinel P, Fauchereau F, Moreno A, Barbot A, Lathrop M, Zelenika D, Le Bihan D, Poline J-B, Bourgeron T, Dehaene S. Genetic variants of FOXP2 and KIAA0319/TTRAP/THEM2 locus are associated with altered brain activation in distinct language-related regions. J Neurosci. 2012; 32:817-825. [PubMed: 22262880]

16. Paracchini S, Thomas A, Castro S, Lai C, Paramasivam M, Wang Y, Keating BJ, Taylor JM, Hacking DF, Scerri T. The chromosome 6p22 haplotype associated with dyslexia reduces the expression of KIAA0319, a novel gene involved in neuronal migration. Hum Mol Genet. 2006; 15:1659-1666. [PubMed: 16600991]

17. Wang Y, Paramasivam M, Thomas A, Bai J, Kaminen-Ahola N, Kere J, Voskuil J, Rosen G, Galaburda A, Loturco J. DYX1C1 functions in neuronal migration in developing neocortex. Neuroscience. 2006; 143:515-522. [PubMed: 16989952]

18• Centanni TM, Booker AB, Sloan AM, Chen F, Maher B, Carraway R, Khodaparast N, Rennaker R, LoTurco J, Kilgard M. Knockdown of the dyslexia-associated gene Kiaa0319 impairs temporal responses to speech stimuli in rat primary auditory cortex. Cereb Cortex. 2014; 24:1753-1766. In this study, in utero disruption of the dyslexia susceptibility gene KIAA0319 expression in rats resulted in poor neural representation of speech sounds in the auditory cortex. The resulting deficits of high variability of speech responses and reduced the neural discrimination ability of speech sounds resemble those that have been reported for human individuals with dyslexia and supports a direct link between the dyslexia susceptibility genes and function crucial for learning to read. [PubMed: 23395846]

19. Centanni TM, Booker AB, Chen F, Sloan AM, Carraway RS, Rennaker RL, LoTurco JJ, Kilgard MP. Knockdown of Dyslexia-Gene Dcdc2 interferes with speech sound discrimination in continuous streams. J Neurosci. 2016; 36:4895-4906. [PubMed: 27122044]

20. Centanni TM, Chen F, Booker AM, Engineer CT, Sloan AM, Rennaker RL, LoTurco JJ, Kilgard MP. Speech sound processing deficits and training-induced neural plasticity in rats with dyslexia gene knockdown. PLoS ONE. 2014; 9:e98439. [PubMed: 24871331]

21. Hornickel J, Kraus N. Unstable representation of sound: a biological marker of dyslexia. J Neurosci. 2013; 33:3500-3504. [PubMed: 23426677]

22. Czamara D, Bruder J, Becker J, Bartling J, Hoffmann P, Ludwig KU, Müller-Myhsok B, SchulteKörne G. Association of a rare variant with mismatch negativity in a region between KIAA0319 and DCDC2 in dyslexia. Behav Genet. 2011; 41:110-119. [PubMed: 21104116]

23. Darki F, Peyrard-Janvid M, Matsson H, Kere J, Klingberg T. Three dyslexia susceptibility genes, DYX1C1, DCDC2, and KIAA0319, affect temporo-parietal white matter structure. Biol Psychiatry. 2012; 72:671-676. [PubMed: 22683091]

24. Jahanshad N, Kochunov PV, Sprooten E, Mandl RC, Nichols TE, Almasy L, Blangero J, Brouwer RM, Curran JE, de Zubicaray GI. Multi-site genetic analysis of diffusion images and voxelwise heritability analysis: a pilot project of the ENIGMA-DTI working group. Neuroimage. 2013; 81:455-469. [PubMed: 23629049]

25. Scerri TS, Darki F, Newbury DF, Whitehouse AJ, Peyrard-Janvid M, Matsson H, Ang QW, Pennell CE, Ring S, Stein J. The dyslexia candidate locus on 2p12 is associated with general cognitive ability and white matter structure. PLoS ONE. 2012; 7:e50321. [PubMed: 23209710]

26••. Swanson MR, Wolff JJ, Elison JT, Gu H, Hazlett HC, Botteron K, Styner M, Paterson S, Gerig G, Constantino J. Splenium development and early spoken language in human infants. Dev Sci. 2015 This study examined the development of several white matter tracts in infants from 6 
months to 24 months. Results demonstrated a significant association between the development of the splenium of the corpus callosum, an interhemispheric tract connecting the default mode network with visual cortices, and language production. This region is thought to support rapid visual orientation. These findings establish the importance of domain-general attention mechanisms of early language acquisition. The study also establishes the feasibility and promise of longitudinal infant neuroimaging research in investigating early biomarkers of developmental disorders.

27. Bruder GE, Keilp JG, Xu H, Shikhman M, Schori E, Gorman JM, Gilliam TC. Catechol-Omethyltransferase (COMT) genotypes and working memory: associations with differing cognitive operations. Biol Psychiatry. 2005; 58:901-907. [PubMed: 16043133]

28. Sundermann EE, Levran O, Robinson-Papp J, Bishop JR, Kreek MJ, Morgello S. Association between the Catechol-O-Methyltransferase (COMT) gene variant, Val158Met, and motor deficits in HIV plus patients. J Neurovirol. 2009:96-96.

29. Landi N, Frost SJ, Mencl WE, Preston JL, Jacobsen LK, Lee M, Yrigollen C, Pugh KR, Grigorenko EL. The COMT Val/Met polymorphism is associated with reading-related skills and consistent patterns of functional neural activation. Dev Sci. 2013; 16:13-23. [PubMed: 23278923]

30. Lai CS, Gerrelli D, Monaco AP, Fisher SE, Copp AJ. FOXP2 expression during brain development coincides with adult sites of pathology in a severe speech and language disorder. Brain. 2003; 126:2455-2462. [PubMed: 12876151]

31. Kovas Y, Plomin R. Generalist genes: implications for the cognitive sciences. Trends Cogn Sci. 2006; 10:198-203. [PubMed: 16580870]

32. Plomin R, Kovas Y. Generalist genes and learning disabilities. Psychol Bull. 2005; 131:592. [PubMed: 16060804]

33. Hu WF, Chahrour MH, Walsh CA. The diverse genetic landscape of neurodevelopmental disorders. Ann Rev Genom Hum Genet. 2014; 15:195-213.

34. Fox SE, Levitt P, Nelson CA 3rd. How the timing and quality of early experiences influence the development of brain architecture. Child Dev. 2010; 81:28-40. [PubMed: 20331653]

35. Pugh KR, Mencl WE, Jenner AR, Katz L, Frost SJ, Lee JR, Shaywitz SE, Shaywitz BA. Neurobiological studies of reading and reading disability. J Commun Disord. 2001; 34:479-492. [PubMed: 11725860]

36. Dehaene S, Cohen L. The unique role of the visual word form area in reading. Trends Cogn Sci. 2011; 15:254-262. [PubMed: 21592844]

37. Price CJ, Devlin JT. The interactive account of ventral occipitotemporal contributions to reading. Trends Cogn Sci. 2011; 15:246-253. [PubMed: 21549634]

38. Binder JRD, RH. The neurobiolgoy of semantic memory. Trends Cogn Sci. 2011; 15:527-536. [PubMed: 22001867]

39. Price CJ. A review and synthesis of the first 20 years of PET and fMRI studies of heard speech, spoken language and reading. NeuroImage. 2012; 62:816-847. [PubMed: 22584224]

40. Rimrodt SL, Clements-Stephens AM, Pugh KR, Courtney SM, Gaur P, Pekar JJ, Cutting LE. Functional MRI of sentence comprehension in children with dyslexia: beyond word recognition. Cereb Cortex. 2009; 19:402-413. [PubMed: 18515796]

41. Aron AR, Monsell S, Sahakian BJ, Robbins TW. A componential analysis of task-switching deficits associated with lesions of left and right frontal cortex. Brain. 2004; 127:1561-1573. [PubMed: 15090477]

42. Bitan T, Burman DD, Chou TL, Lu D, Cone NE, Cao F, Bigio JD, Booth JR. The interaction between orthographic and phonological information in children: an fMRI study. Hum Brain Mapp. 2007; 28:880-891. [PubMed: 17133384]

43. Bitan TB, Burman DD, Chou TL, Lu D, Cone NE, Cao F, Booth JR. The interaction between orthographic and phonological information in children: an fMRI study. Hum Brain Mapp. 2007; 28:880-891. [PubMed: 17133384]

44. Booth JR, Burman DD, Santen FWV, Harasaki Y, Gitelman DR, Parrish TB, Mesulam MM. The development of specialized brain systems in reading and oral-language. Child Neuropsychol. 2001; 7:119-141. [PubMed: 12187470] 
45. Turkeltaub PE, Gareau L, Flowers DL, Zeffiro TA, Eden GF. Development of neural mechanisms for reading. Nat Neurosci. 2003; 6:767-773. [PubMed: 12754516]

46. Richlan F, Kronbichler M, Wimmer H. Meta-analyzing brain dysfunctions in dyslexic children and adults. NeuroImage. 2011; 56:1735-1742. [PubMed: 21338695]

47. Richlan F, Kronbichler M, Wimmer H. Structural abnormalities in the dyslexic brain: a metaanalysis of voxel-based morphometry studies. Hum Brain Mapp. 2013; 34:3055-3065. [PubMed: 22711189]

48. Hoeft F, Hernandez A, McMillon G, Taylor-Hill H, Martindale JL, Meyler A, Keller TA, Siok WT, Deutsch GK, Just MA. Neural basis of dyslexia: a comparison between dyslexic and nondyslexic children equated for reading ability. J Neurosci. 2006; 26:10700-10708. [PubMed: 17050709]

49. Hoeft F, Meyler A, Hernandez A, Juel C, Taylor-Hill H, Martindale JL, McMillon G, Kolchugina G, Black JM, Faizi A. Functional and morphometric brain dissociation between dyslexia and reading ability. Proc Natl Acad Sci. 2007; 104:4234-4239. [PubMed: 17360506]

50. Krafnick AJ, Flowers DL, Luetje MM, Napoliello EM, Eden GF. An investigation into the origin of anatomical differences in dyslexia. J Neurosci. 2014; 34:901-908. [PubMed: 24431448]

51. Clark CA, Helland T, Specht K, Narr KL, Manis FR, Toga AW, Hugdahl K. Neuroanatomical precursors of dyslexia identified from pre-reading through age to 11. Brain. 2014:awu229.

52. Klingberg T, Hedehus M, Temple E, Salz T, Gabrieli JD, Moseley ME, Poldrack RA. Microstructure of temporo-parietal white matter as a basis for reading ability: evidence from diffusion tensor magnetic resonance imaging. Neuron. 2000; 25:493-500. [PubMed: 10719902]

53. Rimrodt SL, Peterson DJ, Denckla MB, Kaufmann WE, Cutting LE. White matter microstructural differences linked to left perisylvian language network in children with dyslexia. Cortex. 2010; 46:739-749. [PubMed: 19682675]

54. Steinbrink C, Vogt K, Kastrup A, Muller HP, Juengling FD, Kassubek J, Riecker A. The contribution of white and gray matter differences to developmental dyslexia: insights from DTI and VBM at 3. 0 T. Neuropsychologia. 2008; 46:3170-3178. [PubMed: 18692514]

55. Yeatman JD, Dougherty RF, Rykhlevskaia E, Sherbondy AJ, Deutsch GK, Wandell BA, BenShachar M. Anatomical properties of the arcuate fasciculus predict phonological and reading skills in children. J Cogn Neurosci. 2011; 23:3304-3317. [PubMed: 21568636]

56••. Wang Y, Mauer MV, Raney T, Peysakhovich B, Becker BL, Sliva DD, Gaab N. Development of tract-specific white matter pathways during early reading development in at-risk children and typical controls. Cereb Cortex. 2016; 1:17. This study examined the development of tract-specific white matter pathways from the pre-reading to the fluent reading stage in children at familial risk for dyslexia (FHD+) versus controls (FHD-) cross-sectionally and longitudinally. Results demonstrated white matter alterations and atypical lateralization of the arcuate fasciculus at the pre-reading stage in FHD+ versus FHD- children. Moreover, faster white matter development in subsequent good versus poor readers and a positive association between white matter maturation and reading development were observed. Additionally, the combination of white matter maturation, familial risk, and psychometric measures was shown to best predict later reading abilities. Furthermore, within FHD+ children, subsequent good compared to poor readers exhibited faster white matter development in the right superior longitudinal fasciculus, suggesting compensatory mechanisms. The findings highlight the importance of white matter pathway maturation in typical and atypical reading development.

57. Schurz M, Wimmer H, Richlan F, Ludersdorfer P, Klackl J, Kronbichler M. Resting-state and taskbased functional brain connectivity in developmental dyslexia. Cereb Cortex. 2014:bhu184.

58. Finn ES, Shen X, Holahan JM, Scheinost D, Lacadie C, Papdemetris X, Constable RT. Disruption of functional networks in dyslexia: a whole-brain data-driven analysis of connectivity. Biol Psychiatry. 2014; 76:397-404. [PubMed: 24124929]

59••. Im K, Raschle NM, Smith SA, Grant PE, Gaab N. Atypical sulcal pattern in children with developmental dyslexia and at-risk kindergartners. Cereb Cortex. in press. This study characterized the sulcal patterns (the arrangement, number, and size of primary cortical folds) of preschool children with a family history of dyslexia and older children with dyslexia. Results demonstrated atypical sulcal patterns in temporo-parietal and occipito-temporal regions in FHD+ pre-readers as compared to FHD- pre-readers, and the same patterns were observed in older children with dyslexia. Sulcal pattern has been hypothesized to relate to optimal organization of 
cortical function and white matter connectivity and is largely determined during prenatal development. These findings support the role of genetic risk for dyslexia in affecting atypical brain development.

60••. Langer N, Peysakhovich B, Zuk J, Drottar M, Sliva DD, Smith S, Becker B, Grant E, Gaab N. White matter alterations in infants at risk for developmental dyslexia. Cereb Cortex. in press. This study demonstrated that white matter alterations reported for individuals with dyslexia, are already present in 18-month-old infants with a family history of dyslexia. These findings provide evidence that genetic risk for dyslexia is associated with atypical brain development in neural structures important for reading.

61. Molfese DL. Predicting dyslexia at 8 years of age using neonatal brain responses. Brain Lang. 2000; 72:238-245. [PubMed: 10764519]

62. Leppanen PH, Hamalainen JA, Salminen HK, Eklund KM, Guttorm TK, Lohvansuu K, Puolakanaho A, Lyytinen H. Newborn brain event-related potentials revealing atypical processing of sound frequency and the subsequent association with later literacy skills in children with familial dyslexia. Cortex. 2010; 46:1362-1376. [PubMed: 20656284]

63. Leppanen PH, Hamalainen JA, Guttorm TK, Eklund KM, Salminen H, Tanskanen A, Torppa M, Puolakanaho A, Richardson U, Pennala R, Lyytinen H. Infant brain responses associated with reading-related skills before school and at school age. Neurophysiol Clin. 2012; 42:35-41. [PubMed: 22200340]

64. Leppanen PH, Pihko E, Eklund KM, Lyytinen H. Cortical responses of infants with and without a genetic risk for dyslexia: II. Group effects. Neuroreport. 1999; 10:969-973. [PubMed: 10321469]

65. Richardson U, Leppanen PH, Leiwo M, Lyytinen H. Speech perception of infants with high familial risk for dyslexia differ at the age of 6 months. Dev Neuropsychol. 2003; 23:385-397. [PubMed: 12740192]

66. Guttorm TK, Leppanen PH, Hamalainen JA, Eklund KM, Lyytinen HJ. Newborn event-related potentials predict poorer pre-reading skills in children at risk for dyslexia. J Learn Disabil. 2010; 43:391-401. [PubMed: 19890075]

67. Molfese VJ, Molfese DL, Modgline AA. Newborn and preschool predictors of second-grade reading scores: an evaluation of categorical and continuous scores. J Learn Disabil. 2001; 34:545554. [PubMed: 15503569]

68. van Zuijen TL, Plakas A, Maassen BA, Maurits NM, van der Leij A. Infant ERPs separate children at risk of dyslexia who become good readers from those who become poor readers. Dev Sci. 2013; 16:554-563. [PubMed: 23786473]

69. Raschle N, Chang M, Gaab N. Structural brain alterations associated with dyslexia predate reading onset. Neuroimage. 2011; 57:742-749. [PubMed: 20884362]

70. Raschle NM, Zuk J, Gaab N. Functional characteristics of developmental dyslexia in lefthemispheric posterior brain regions predate reading onset. Proc Natl Acad Sci U S A. 2012; 109:2156-2161. [PubMed: 22308323]

71. Bach S, Richardson U, Brandeis D, Martin E, Brem S. Print-specific multimodal brain activation in kindergarten improves prediction of reading skills in second grade. Neuroimage. 2013; 82:605615. [PubMed: 23727320]

72. Yamada Y, Stevens C, Dow M, Harn BA, Chard DJ, Neville HJ. Emergence of the neural network for reading in five-year-old beginning readers of different levels of pre-literacy abilities: an fMRI study. Neuroimage. 2011; 57:704-713. [PubMed: 20977940]

73•. Pugh KR, Frost SJ, Rothman DL, Hoeft F, Del Tufo SN, Mason GF, Molfese PJ, Mencl WE, Grigorenko EL, Landi N. Glutamate and choline levels predict individual differences in reading ability in emergent readers. J Neurosci. 2014; 34:4082-4089. This is the first study to examine relationship between neurochemistry and reading abiliteisin in the pedatric population. The authors demonstrated that poorer performance in reading and related linguistic measures such as phonology and vocabulary were associated with higher concentrations of choline and glutamate, which might reflect white matter atypicalities and hyperexcitability in children with atypical reading ablities. Such findings illuminate the signifiance of investigating DD from a gene-brainbehavior perspective. [PubMed: 24623786] 
74. Laycock SK, Wilkinson ID, Wallis LI, Darwent G, Wonders SH, Fawcett AJ, Griffiths PD, Nicolson RI. Cerebellar volume and cerebellar metabolic characteristics in adults with dyslexia. Ann N Y Acad Sci. 2008; 1:222-236.

75. Bruno JL, Lu Z-L, Manis FR. Phonological processing is uniquely associated with neuro-metabolic concentration. NeuroImage. 2013; 67:175-181. [PubMed: 23147236]

76. Perlov E, van Elst LT, Buechert M, Maier S, Matthies S, Ebert D, Hesslinger B, Philipsen A. H 1MR-spectroscopy of cerebellum in adult attention deficit/hyperactivity disorder. J Psychiatric Res. 2010; 44:938-943.

77. Miller D, Thomas R, Frazier M. Single strand breaks in CHO cell DNA induced by ultrasonic cavitation in vitro. Ultrasound Med Biol. 1991; 17:401-406. [PubMed: 1949351]

78. Kreis R, Ernst T, Ross BD. Development of the human brain: in vivo quantification of metabolite and water content with proton magnetic resonance spectroscopy. Magn Res Med. 1993; 30:424437.

79. Filippi CG, Uluğ AM, Deck MD, Zimmerman RD, Heier LA. Developmental delay in children: assessment with proton MR spectroscopy. Am J Neuroradiol. 2002; 23:882-888. [PubMed: 12006297]

80. Kruse B, Barker PB, van Zijl P, Duyn JH, Moonen CT, Moser HW. Multislice proton magnetic resonance spectroscopic imaging in X-linked adrenoleukodystrophy. Ann Neurol. 1994; 36:595_ 608. [PubMed: 7944292]

81. Erecińska M, Silver IA. Metabolism and role of glutamate in mammalian brain. Prog Neurobiol. 1990; 35:245-296. [PubMed: 1980745]

82. Ueda Y, Tokumaru J, Yokoyama H, Nakajima A, Mitsuyama Y, Ohya-Nishiguchi H, Kamada H, Willmore LJ. Collapse of extracellular glutamate regulation during epileptogenesis: downregulation and functional failure of glutamate transporter function in rats with chronic seizures induced by kainic acid. J Neurochem. 2001; 76:892-900. [PubMed: 11158261]

83. Blüml S, Wisnowski JL, Nelson MD, Paquette L, Gilles FH, Kinney HC, Panigrahy A. Metabolic maturation of the human brain from birth through adolescence: insights from in vivo magnetic resonance spectroscopy. Cereb Cortex. 2013; 23:2944-2955. [PubMed: 22952278]

84. Sperling AJ, Lu Z-L, Manis FR, Seidenberg MS. Motion-perception deficits and reading impairment it's the noise, not the motion. Psychol Sci. 2006; 17:1047-1053. [PubMed: 17201786]

85. Pugh KR, Landi N, Preston JL, Mencl WE, Austin AC, Sibley D, Fulbright RK, Seidenberg MS, Grigorenko EL, Constable RT. The relationship between phonological and auditory processing and brain organization in beginning readers. Brain Lang. 2013; 125:173-183. [PubMed: 22572517]

86. Che A, Truong DT, Fitch RH, LoTurco JJ. Mutation of the dyslexia-associated gene Dcdc2 enhances glutamatergic synaptic transmission between layer 4 neurons in mouse neocortex. Cereb Cortex. 2015:bhv168.

87. Peterson RL, Pennington BF. Developmental Dyslexia. Ann Rev Clin Psychol. 2015; 11:283-307. [PubMed: 25594880]

88. Wolf M, Bowers PG. The double-deficit hypothesis for the developmental dyslexias. J Educ Psychol. 1999; 91:415.

89. Scarborough HS. Very early language deficits in dyslexic children. Child Dev. 1990; 61:17281743. [PubMed: 2083495]

90. Pennington BF, Lefly DL. Early reading development in children at family risk for dyslexia. Child Dev. 2001; 72:816-833. [PubMed: 11405584]

91. Raschle NM, Becker BLC, Smith S, Fehlbaum LV, Wang Y, Gaab N. Investigating the influences of language delay and/or familial risk for dyslexia on brain structure in 5-year-olds. Cerebral Cortex. in press.

92. Catts HW, Adlof SM, Hogan TP, Weismer SE. Are specific language impairment and dyslexia distinct disorders? J Speech Lang Hear Res. 2005; 48:1378-1396. [PubMed: 16478378]

93. Bishop DV, Snowling MJ. Developmental dyslexia and specific language impairment: same or different? Psychol Bull. 2004; 130:858. [PubMed: 15535741]

94. Ramus F, Marshall CR, Rosen S, van der Lely HK. Phonological deficits in specific language impairment and developmental dyslexia: towards a multidimensional model. Brain. 2013; 136:630-645. [PubMed: 23413264] 
95. Scarborough HS. Predicting the future achievement of second graders with reading disabilities: contributions of phonemic awareness, verbal memory, rapid naming, and IQ. Ann Dyslexia. 1998; 48:115-136.

96. Boets B, Wouters J, Van Wieringen A, Ghesquière P. Auditory temporal information processing in preschool children at family risk for dyslexia: relations with phonological abilities and developing literacy skills. Brain Lang. 2006; 97:64-79. [PubMed: 16112723]

97. McBride-Chang C, Manis FR. Structural invariance in the associations of naming speed, phonological awareness, and verbal reasoning in good and poor readers: a test of the double deficit hypothesis. Read Writing. 1996; 8:323-339.

98. Stahl SA, Murray BA. Defining phonological awareness and its relationship to early reading. J Educ Psychol. 1994; 86:221.

99. Savage R, Lavers N, Pillay V. Working memory and reading difficulties: what we know and what we don't know about the relationship. Educ Psychol Rev. 2007; 19:185-221.

100••. Moll K, Loff A, Snowling MJ. Cognitive endophenotypes of dyslexia. Scient Stud Read. 2013; 17:385-397. This study addressed the question of which cognitive deficits in dyslexia are associated with hereditary risk for dyslexia and which are associated with actual reading outcomes. Results demonstrated that in school-aged children with and without a family history of dyslexia, measures of word recall, morphology, and rapid automatized naming were associated with reading outcomes, but measures of phonology were associated with genetic risk and reading outcomes. These results have important implications for the multi-deficit approach to dyslexia.

101. Snowling MJ, Melby-Lervåg M. Oral language deficits in familial dyslexia: a meta-analysis and review. Psycol Bull. 2016

102. Moll KLA, Snowling MJ. Cognitive endophenotypes of dyslexia. Scient Stud Read. 2013; 17:385-597.

103. Boets B, Wouters J, van Wieringen A, Ghesquiere P. Auditory processing, speech perception and phonological ability in pre-school children at high-risk for dyslexia: a longitudinal study of the auditory temporal processing theory. Neuropsychologia. 2007; 45:1608-1620. [PubMed: 17303197]

104. Boets B, Wouters J, Van Wieringen A, Ghesquiere P. Auditory processing, speech perception and phonological ability in pre-school children at high-risk for dyslexia: a longitudinal study of the auditory temporal processing theory. Neuropsychologia. 2007; 45:1608-1620. [PubMed: 17303197]

105. Wolf, M.; Denckla, MB. The Rapid Automatized Naming and Rapid Alternating Stimulus Tests: Examiner's Manual. Pro-ed; 2005.

106. Denckla MB, Rudel RG. Rapid 'automatized' naming (RAN): dyslexia differentiated from other learning disabilities. Neuropsychologia. 1976; 14:471-479. [PubMed: 995240]

107. Van Bergen E, de Jong PF, Plakas A, Maassen B, van der Leij A. Child and parental literacy levels within families with a history of dyslexia. J Child Psychol Psychiatry. 2012; 53:28-36. [PubMed: 21615405]

108. McBride-Chang C. The ABCs of the ABCs: the development of letter name and letter sound knowledge. Merrill-Palmer Quart. 1999; 45:2.

109. Wagner, RK.; Barker, TA. The Varieties of Orthographic Knowledge. Springer; 1994. The development of orthographic processing ability; p. 243-276.

110. Senechal M, leFevre J. Parental involvement in development of children's reading skills: a five year longitudinal study. Child Dev. 2002; 73:445-460. [PubMed: 11949902]

111. Banai K, Hornickel J, Skoe E, Nicol T, Zecker S, Kraus N. Reading subcortical auditory function. Cereb Cortex. 2009; 19:2699-2707. [PubMed: 19293398]

112. Bishop D, Carlyon R, Deeks J, Bishop S. Auditory temporal processing impairmentneither necessary nor sufficient for causing language impairment in children. J Speech Lang Hear Res. 1999; 42:1295-1310. [PubMed: 10599613]

113. Tallal P. Improving language and literacy is a matter of time. Nat Rev Neurosci. 2004; 5:721-728. [PubMed: 15322530]

114. Goswami U. A temporal sampling framework for developmental dyslexia. Trends Cogn Sci. 2011; 15:3-10. [PubMed: 21093350] 
115. Gori S, Seitz AR, Ronconi L, Franceschini S, Facoetti A. Multiple causal links between magnocellular — dorsal pathway deficit and developmental dyslexia. Cereb Cortex. 2015:bhv206. [PubMed: 26400914]

116. Raschle N, Stering PL, Meissner S, Gaab N. Altered neuronal response during rapid auditory processing and its relation to phonological processing in pre-reading children at familial risk for dyslexia. Cereb Cortex. 2013

117. Boets B, Vandermosten M, Poelmans H, Luts H, Wouters J, Ghesquière P. Preschool impairments in auditory processing and speech perception uniquely predict future reading problems. Res Dev Disabil. 2011; 32:560-570. [PubMed: 21236633]

118. Plakas A, van Zuijen T, van Leeuwen T, Thomson JM, van der Leij A. Impaired non-speech auditory processing at a pre-reading age is a risk-factor for dyslexia but not a predictor: an ERP study. Cortex. 2013; 49:1034-1045. [PubMed: 22542727]

119. van Zuijen TL, Plakas A, Maassen BA, Been P, Maurits NM, Krikhaar E, van Driel J, van der Leij A. Temporal auditory processing at 17 months of age is associated with preliterate language comprehension and later word reading fluency: an ERP study. Neurosci Lett. 2012; 528:31-35. [PubMed: 22981882]

120. Tallal P. Auditory temporal perception, phonics, and reading disabilities in children. Brain Lang. 1980; 9:182-198. [PubMed: 7363063]

121. Tallal P, Gaab N. Dynamic auditory processing, musical experience and language development. Trends Neurosci. 2006; 29:382-390. [PubMed: 16806512]

122. Corriveau KG, Goswami U, Thomson J. Auditory processing and early literature skill in a preschool and kindergarten population. J Learn Disabil. 2010; 43:369-382. [PubMed: 20457882]

123. Goswami U. Phonology, reading development, and dyslexia: a cross-linguistic perspective. Ann Dyslexia. 2002; 52:141-163.

124. Tierney AT, Kraus N. The ability to tap to a beat relates to cognitive, linguistic, and perceptual skills. Brain Lang. 2013; 124:225-231. [PubMed: 23400117]

125. Goswami U, Thomson J, Richardson U, Stainthorp R, Hughes D, Rosen S, Scott SK. Amplitude envelope onsets and developmental dyslexia: a new hypothesis. Proc Natl Acad Sci. 2002; 99:10911-10916. [PubMed: 12142463]

126. Olulade OA, Napoliello EM, Eden GF. Abnormal visual motion processing is not a cause of dyslexia. Neuron. 2013; 79:180-190. [PubMed: 23746630]

127. Boets B, Vandermosten M, Cornelissen P, Wouters J, Ghesquière P. Coherent motion sensitivity and reading development in the transition from prereading to reading stage. Child Dev. 2011; 82:854-869. [PubMed: 21410913]

128. Kevan A, Pammer K. Predicting early reading skills from pre-reading measures of dorsal stream functioning. Neuropsychologia. 2009; 47:3174-3181. [PubMed: 19651148]

129. Ahissar M. Dyslexia and the anchoring-deficit hypothesis. Trends Cogn Sci. 2007; 11:458-465. [PubMed: 17983834]

130. Breznitz, Z. Fluency in Reading: Synchronization of Processes. Routledge; 2006.

131. Plaza MCH. The contribution of phonological awareness and visual attention in early reading and spelling. Dyslexia. 2007; 13:67-76. [PubMed: 17330736]

132. Vidyasagar TR, Pammer K. Dyslexia: a deficit in visuo-spatial attention, not in phonological processing. Trends Cogn Sci. 2010; 14:57-63. [PubMed: 20080053]

133. Franceschini S, Gori S, Ruffino M, Pedrolli K, Facoetti A. A causal link between visual spatial attention and reading acquisition. Curr Biol. 2012; 22:814-819. [PubMed: 22483940]

134. Raizada RD, Kishiyama MM. Effects of socioeconomic status on brain development, and how cognitive neuroscience may contribute to levelling the playing field. Front Hum Neurosci. 2010:4. [PubMed: 20198130]

135. Raizada RD, Richards TL, Meltzoff A, Kuhl PK. Socioeconomic status predicts hemispheric specialisation of the left inferior frontal gyrus in young children. Neuroimage. 2008; 40:13921401. [PubMed: 18308588]

136. Natalie H, Noble KG. Socioeconomic status and structural brain development. Front Neurosci. 2014

Curr Opin Behav Sci. Author manuscript; available in PMC 2017 August 01. 
137••. Noble KG, Houston SM, Brito NH, Bartsch H, Kan E, Kuperman JM, Akshoomoff N, Amaral DG, Bloss CS, Libiger O. Family income, parental education and brain structure in children and adolescents. Nat Neurosci. 2015; 18:773-778. This study demonstrated reduced surface area in the brain of children from lower socioeconomic (SES) backgrounds in regions important for language, reading, executive functions and spatial skills. Since the study controlled for hereditary influences, results could reflect disparities in prenatal and postnatal experiences based on SES and have important implications for policies targeting low-income families. [PubMed: 25821911]

138. Noble KG, Houston SM, Kan E, Sowell ER. Neural correlates of socioeconomic status in the developing human brain. Dev Sci. 2012; 15:516-527. [PubMed: 22709401]

139. Ursache A, Noble KG. Neurocognitive development in socioeconomic context: multiple mechanisms and implications for measuring socioeconomic status. Psychophysiology. 2016; 53:71-82. [PubMed: 26681619]

140. Sheridan MA, Sarsour K, Jutte D, D’Esposito M, Boyce WT. The impact of social disparity on prefrontal function in childhood. PLoS ONE. 2012; 7:e35744. [PubMed: 22563395]

141. Van den Bergh BR, Mulder EJ, Mennes M, Glover V. Antenatal maternal anxiety and stress and the neurobehavioural development of the fetus and child: links and possible mechanisms. A review. Neurosci Biobehav Rev. 2005; 29:237-258. [PubMed: 15811496]

142. Dilnot J, Hamilton L, Maughan B, Snowling MJ. Child and environmental risk factors predicting readiness for learning in children at high risk of dyslexia. Dev Psychopathol. 2016:1-10.

143. Evans MA, Shaw D, Bell M. Home literacy activities and their influence on early literacy skills. Can J Exp Psychol. 2000; 54:65. [PubMed: 10881391]

144. Hamilton, LG. The Role of the Home Literacy Environment in the Early Literacy Development of Children at Family-risk of Dyslexia. University of UK; 2013.

145. Payne AC, Whitehurst GJ, Angell AL. The role of home literacy environment in the development of language ability in preschool children from low-income families. Early Childhood Res Quart. 1994; 9:427-440.

146. Bracken SS, Fischel JE. Family reading behavior and early literacy skills in preschool children from low-income backgrounds. Early Educ Dev. 2008; 19:45-67.

147. Dearing E, McCartney K, Weiss HB, Kreider H, Simpkins S. The promotive effects of family educational involvement for low-income children's literacy. J School Psychol. 2004; 42:445-460.

148. Hanson MJ, Miller AD, Diamond K, Odom S, Lieber J, Butera G, Horn E, Palmer S, Fleming K. Neighborhood community risk influences on preschool children's development and school readiness. Infants Young Children. 2011; 24:87-100.

149•. Vaden-Kiernan M, D’Elio MA, O’Brien RW, Tarullo LB, Zill N, Hubbell-McKey R. Neighborhoods as a developmental context: a multilevel analysis of neighborhood effects on Head Start families and children. Am J Commun Psychol. 2010; 45:49-67.

150. Froiland JM, Powell DR, Diamond KE, Son SHC. Neighborhood socioeconomic well-being, home literacy, and early literacy skills of at-risk preschoolers. Psychol Schools. 2013; 50:755769. This study demonstrated that socioeconomic factors on a neighborhood level, such as percentage of adults with college education, occupancy rate, and rate of public assistance were associated with the quality of preschoolers home literacy, which in turn predicted childrens early literacy skills.

151. Kohen DE, Brooks-Gunn J, Leventhal T, Hertzman C. Neighborhood income and physical and social disorder in Canada: associations with young children's competencies. Child Dev. 2002:1844-1860. [PubMed: 12487498]

152. Mathes PG, Denton CA, Fletcher JM, Anthony JL, Francis DJ, Schatschneider C. The effects of theoretically different instruction and student characteristics on the skills of struggling readers. Read Res Quart. 2005; 40:148-182.

153. Moats, LC. Teaching Reading Is Rocket Science: What Expert Teachers of Reading Should Know and Be Able To Do. 1999.

154. Dyson L. Unanticipated effects of children with learning disabilities on their families. Learn Dis Quart. 2010; 33:43-55.

155. Karande S, Mehta V, Kulkarni M. Impact of an education program on parental knowledge of specific learning disability. Ind J Med Sci. 2007; 61:398. 
156. Petrill SA, Deater-Deckard K, Thompson LA, De Thorne LS, Schatschneider C. Reading skills in early readers genetic and shared environmental influences. J Learn Disabil. 2006; 39:48-55. [PubMed: 16512082]

157. Taylor J, Roehrig A, Hensler BS, Connor C, Schatschneider C. Teacher quality moderates the genetic effects on early reading. Science. 2010; 328:512-514. [PubMed: 20413504]

158. Olson RK, Keenan JM, Byrne B, Samuelsson S. Why do children differ in their development of reading and related skills? Scient Stud Read. 2014; 18:38-54.

159. Jimerson S, Egeland B, Sroufe LA, Carlson B. A prospective longitudinal study of high school dropouts examining multiple predictors across development. J School Psychol. 2000; 38:525549.

160. Dougherty C. Numeracy, literacy and earnings: evidence from the National Longitudinal Survey of Youth. Econ Educ Rev. 2003; 22:511-521.

161. Christle CA, Yell ML. Preventing youth incarceration through reading remediation: issues and solutions. Read Writ Quart. 2008; 24:148-176.

162. Lindgrén SA, Laine M. Cognitive-linguistic performances of multilingual university students suspected of dyslexia. Dyslexia. 2011; 17:184-200. [PubMed: 21500321]

163. Bruck M. Persistence of dyslexics’ phonological awareness deficits. Dev Psychol. 1992; 28:874.

164. Shaywitz SE, Fletcher JM, Holahan JM, Shneider AE, Marchione KE, Stuebing KK, Francis DJ, Pugh KR, Shaywitz BA. Persistence of dyslexia: the Connecticut longitudinal study at adolescence. Pediatrics. 1999; 104:1351-1359. [PubMed: 10585988]

165. Pammer K. Brain mechanisms and reading remediation: more questions than answers. Scientifica. 2014:2014.

166. Nation K, Snowling MJ. Semantic processing and the development of word-recognition skills: evidence from children with reading comprehension difficulties. J Memory Lang. 1998; 39:85101.

167. Torppa M, Eklund K, van Bergen E, Lyytinen H. Late-emerging and resolving dyslexia: a followup study from age 3 to 14. J Abnormal Child Psychol. 2015:1-13.

$168 \bullet$. Frith U, Snowling M. Reading for meaning and reading for sound in autistic and dyslexic children. Br J Dev Psychol. 1983; 1:329-342. This longitudinal study looked at the development of reading ablilites from Grade 2 to Grade 8 . The author discovered four groups of participants: non-dylexia, persistent-dyslexia, late emerging (developed DD only after Grade 2) and resovling (had DD at Grade 2 but no longer at Grade 8) groups. Retrospective analyses on the children and parental reading and reading-related ablities as well as environmental factors revealed disctinctive factors contributing to the developmental profiles of each group. This findings show the instabilites in the diagnosis of DD, and call for the continued monitoring of children's progress in reading acqusition after the early school years.

169. Muter V, Snowling MJ. Children at familial risk of dyslexia: practical implications from an at-risk study. Child Adolesc Mental Health. 2009; 14:37-41.

170. Hoeft F, McCandliss BD, Black JM, Gantman A, Zakerani N, Hulme C, Lyytinen H, WhitfieldGabrieli S, Glover GH, Reiss AL, Gabrieli JD. Neural systems predicting long-term outcome in dyslexia. Proc Natl Acad Sci U S A. 2011; 108:361-366. [PubMed: 21173250]

171. Temple E, Deutsch GK, Poldrack RA, Miller SL, Tallal P, Merzenich MM, Gabrieli JD. Neural deficits in children with dyslexia ameliorated by behavioral remediation: evidence from functional MRI. Proc Natl Acad Sci. 2003; 100:2860-2865. [PubMed: 12604786]

172. Heim S, Wehnelt A, Grande M, Huber W, Amunts K. Effects of lexicality and word frequency on brain activation in dyslexic readers. Brain Lang. 2013; 125:194-202. [PubMed: 22230039]

173•. Barquero LA, Davis N, Cutting LE. Neuroimaging of reading intervention: a systematic review and activation likelihood estimate meta-analysis. PLoS ONE. 2014; 9:e83668. This meta-analysis synthesizes findings from neuroimaging studies of brain responses to reading intervention. Normalization of neural atypicalities in dyslexia in response to intervention has been demonstrated across studies and has implications for the design of interventions to target individual profiles of neural alterations in dyslexia. [PubMed: 24427278]

174. Burden R. Is dyslexia necessarily associated with negative feelings of self-worth? A review and implications for future research. Dyslexia. 2008; 14:188-196. [PubMed: 18646275] 
175. Goswami U. Neuroscience and education: from research to practice? Nat Rev Neurosci. 2006; 7:406-413. [PubMed: 16607400]

176. Howard-Jones PA. Neuroscience and education: myths and messages. Nat Rev Neurosci. 2014

177. He Q, Xue G, Chen C, Chen C, Lu Z-L, Dong Q. Decoding the neuroanatomical basis of reading ability: a multivoxel morphometric study. J Neurosci. 2013; 33:12835-12843. [PubMed: 23904618]

178. Turkeltaub PE, Gareau L, Flowers DL, Zeffiro TA, Eden GF. Development of neural mechanisms for reading. Nat Neurosci. 2003; 6:767-773. [PubMed: 12754516]

179. Jednoróg K, Gawron N, Marchewka A, Heim S, Grabowska A. Cognitive subtypes of dyslexia are characterized by distinct patterns of grey matter volume. Brain Struct Funct. 2014; 219:16971707. [PubMed: 23775490]

180. Norton ES, Black JM, Stanley LM, Tanaka H, Gabrieli JD, Sawyer C, Hoeft F. Functional neuroanatomical evidence for the double-deficit hypothesis of developmental dyslexia. Neuropsychologia. 2014; 61:235-246. [PubMed: 24953957]

181. Rowe ML. A longitudinal investigation of the role of quantity and quality of child-directed speech in vocabulary development. Child Dev. 2012; 83:1762-1774. [PubMed: 22716950]

182. Hutton JS, Horowitz-Kraus T, Mendelsohn AL, DeWitt T, Holland SK. Home reading environment and brain activation in preschool children listening to stories. Pediatrics. 2015; 136:466-478. [PubMed: 26260716]

183. Black JM, Myers CA, Hoeft F. The utility of neuroimaging studies for informing educational practice and policy in reading disorders. Global Context New Directions Child Adolesc Dev. 2015; 147:49-56.

184••. Myers CA, Vandermosten M, Farris EA, Hancock R, Gimenez P, Black JM, Casto B, Drahos M, Tumber M, Hendren RL. White matter morphometric changes uniquely predict children's reading acquisition. Psychol Sci. 2014; 25:1870-1883. This longitudinal study demonstrated that developmental increases in white matter volume in regions important for reading from kindergarten to $3 \mathrm{rd}$ grade account for a unique variance in predicting reading outcomes, above behavioral measures. This suggests that neuroimaging methods can enhance early identification of dyslexia risk. [PubMed: 25212581]

185. Maurer U, Bucher K, Brem S, Benz R, Kranz F, Schulz E, van der Mark S, Steinhausen H-C, Brandeis D. Neurophysiology in preschool improves behavioral prediction of reading ability throughout primary school. Biol Psychiatry. 2009; 66:341-348. [PubMed: 19423082]

186. Schatschneider C, Fletcher JM, Francis DJ, Carlson CD, Foorman BR. Kindergarten prediction of reading skills: a longitudinal comparative analysis. J Educ Psychol. 2004; 96:265-282.

187. Torgesen JK. Individual differences in response to early interventions in reading: the lingering problem of treatment resisters. Learn Disabil Res Practice. 2000; 15:55-64.

188. Wanzek J, Vaughn S. Research-based implications from extensive early reading interventions. School Psychol Rev. 2007; 36:541.

189. Blair C. School readiness: integrating cognition and emotion in a neurobiological conceptualization of children's functioning at school entry. Am Psychol. 2002; 57:111. [PubMed: 11899554]

190. Noble KG, Tottenham N, Casey B. Neuroscience perspectives on disparities in school readiness and cognitive achievement. Future Children. 2005; 15:71-89.

191. Noble, KG. Cerebrum: the Dana forum on Brain Science. Dana Foundation; 2014. Rich man, poor man: socioeconomic adversity and brain development.

192. Denton, C. Responsive Reading Instruction: Flexible Intervention for Struggling Readers in the Early Grades. Sopris West Educational Services; 2006.

193. Vaughn S, Fuchs LS. Redefining learning disabilities as inadequate response to instruction: the promise and potential problems. Learn Disabil Res Practice. 2003; 18:137-146.

194••. Gabrieli JD, Ghosh SS, Whitfield-Gabrieli S. Prediction as a humanitarian and pragmatic contribution from human cognitive neuroscience. Neuron. 2015; 85:11-26. This review summarizes and evaluates evidence to date on the utility of neuroimaging methods in prediction of individual outcomes across domains such as educational outcomes, criminality, and response to mental health treatments. [PubMed: 25569345] 
195. Rezaie R, Simos PG, Fletcher JM, Cirino PT, Vaughn S, Papanicolaou AC. Temporo-parietal brain activity as a longitudinal predictor of response to educational interventions among middle school struggling readers. J Int Neuropsychol Soc. 2011; 17:875-885. [PubMed: 21740612]

196. Bruer JT. Education and the brain: a bridge too far. Educ Res. 1997:4-16.

197•. Ansari, D. Handbook of Neuroethics. Springer; 2015. Mind, brain, education: a discussion of practical, conceptual, and ethical issues; p. 1703-1719. This chapter described possible translation of neuroscience research of reading into educational practice and highlighted the conceptual and practical challenges in direct application of neuroscience into education. An iterative model of translation that emphasizes effective communication and collaborations between neuroscientists, educational researchers, and practitioners has been proposed 


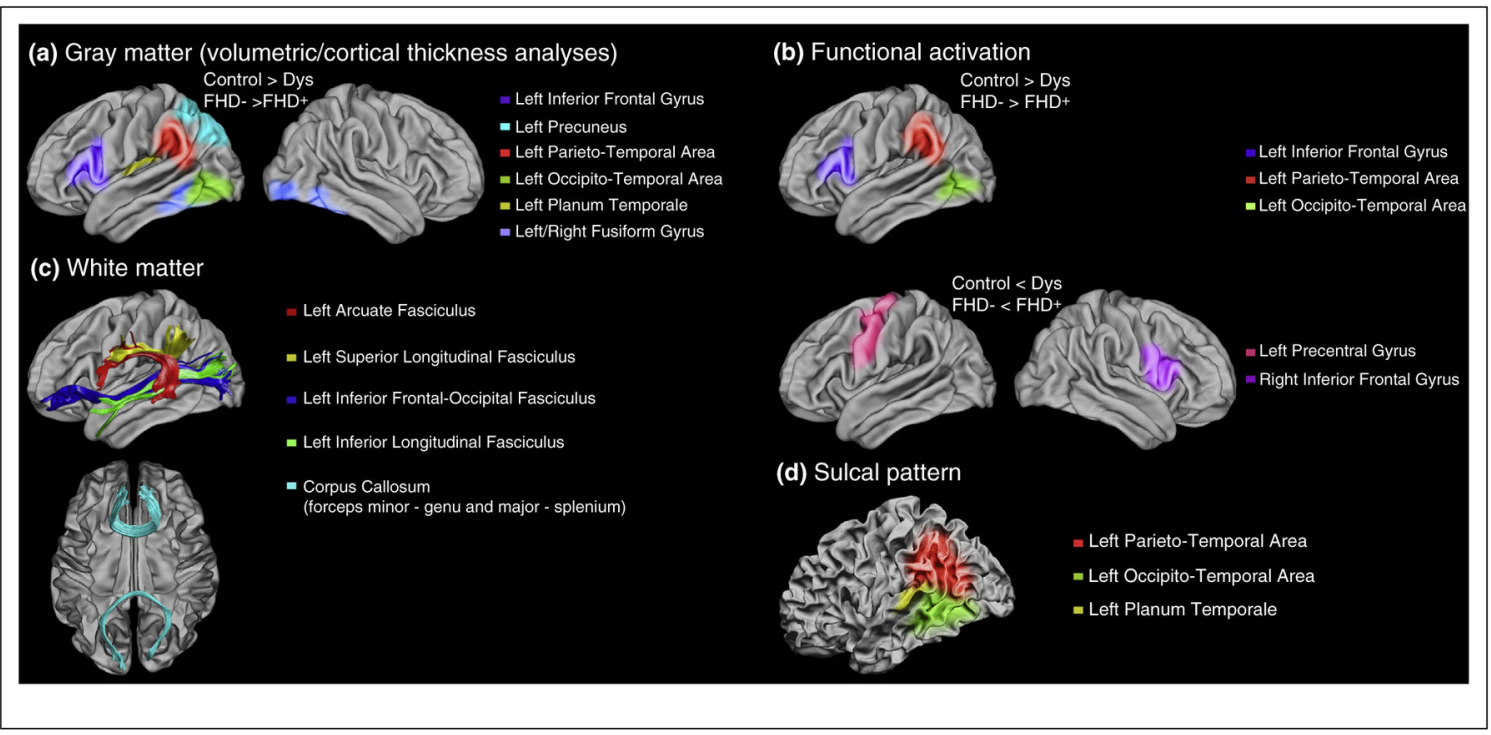

Figure 1.

Structural and functional brain alterations in children with a family history of dyslexia as compared to children without familial risk. Note alterations in the inferior frontal gyrus are only observed when children develop dyslexia. 
Variant function in any number of

Generalist genes, such as COMT, VAL/MEL, FOXP2, and/or

造芯

Dyslexia susceptibility genes, such as ROBO1, DCDC2, DYXICI, KIAA0319

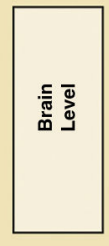

Atypical Atypical axonal

neuronal growth, atypical

migration glutamatergic

and/or transmission,

synaptic/cell subtle focal co

development malformations,

atypical sulcal

pattern, atypic

focal neural

teristics, and/or atypical

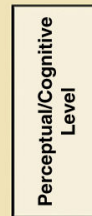

Atypical sensorimotor

perceptual functions

Atypical development Atypical phonological awareness, verbal working memory
of language and/or rapid automatized naming, letter knowledge, vocabulary

attention functions and/or executive functions

๕⿺

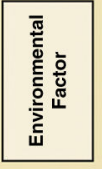

Low home literacy, low parental educational background and socioeconomic status, adverse neighborhood charac-

teristics, and/or cultural influences
Birth
Ineffective schooling, limited instructional resources, and/or insufficient involvement

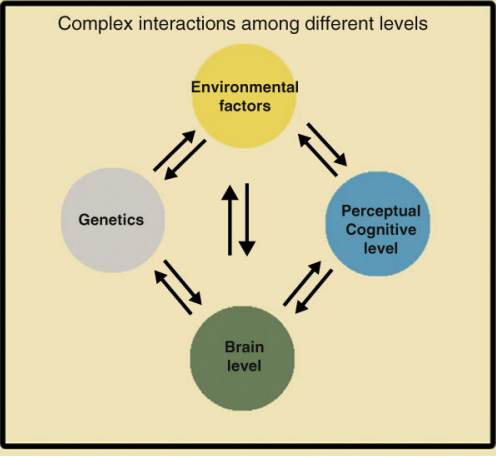

Protective factors and compensatory mechanisms in typical readers with familial risks

Protective (inables efficiency, etc.) Protective cognitive abilities (e.g., high IQ, rich vocabulary, etc.)
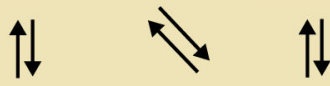

Genetics

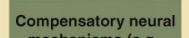

Compensatory neural
mechanisms (e.g., mechanisms (e.g.
ncreased involveme of the right

Figure 2.

Left: a summary of risk factors for dyslexia at the genetic, neural, cognitive, and environmental levels along with a developmental timeline. Top right: a diagram illustration of the reciprocal relationships among the different domains. Bottom right: a diagram illustration of the possible protective factors and compensatory mechanisms for dyslexia. 